\title{
Clinical analysis for the death of 127 patients with acute myocardial infarction and nursing strategies.
}

\author{
Li-Ping Cui ${ }^{1 * \#}$, Lun-Lan Li ${ }^{2 \#}$, An-Qi Liu², Ping Ding², Shao-Hua Hu², Chang-Hui Wang1, Ming-Hua \\ Fang1, Ya Zhang1, Qing-Qing Wang', Shi-Heng Dai', Mei-Rong Liu', Xiao-Shuang Qian' \\ ${ }^{1}$ Department of Cardiovascularology, the First Affiliated Hospital of Medical University of Anhui, Hefei, PR China \\ ${ }^{2}$ Nursing Department, the First Affiliated Hospital of Medical University of Anhui, Hefei, PR China \\ \#These two authors contribute equally to this study
}

\begin{abstract}
How to give the corresponding nursing strategies for the risk factors of death is the focus of the current clinical nursing of AMI. Therefore, this study aims to determine causes of death in patients with Acute Myocardial Infarction (AMI) and the nursing strategies. The clinical data of 127 AMI patients treated in our center from January 1st, 2010 to December 31st, 2014, categorized into observed group and control group according to psychological counselling, were retrospectively analysed. Total of 68 patients were enrolled in observed group with 59 patients enrolled in control group. 48 (70.6\%) of observed group had complicated infection and $43(72.9 \%)$ of control group, respectively. The mortality of observed group was $17.65 \%$, lower than $33.90 \%$ of control group $(p=0.035)$. Multivariate logistic regression analysis indicated that age $(\geq 70 \mathrm{y})$, less-awareness, complicated infection and accompanying conditions such as cardiogenic shock might be high-risk factors of AMI-induced death. In conclusion, AMI deaths are associated with diverse causes. Active and effective nursing approaches, such as psychological counselling, may help to decrease the risk of AMI deaths. The corresponding nursing strategies for these death-related factors included tailored patient education, psychological counselling, concentrated nursing care, reasonable nursing resource planning, continuous ECG monitoring and close observation.
\end{abstract}

Keywords: Acute myocardial infarction, Infection, Psychological counselling, Nursing.

Accepted on May 15, 2018

\section{Introduction}

Acute Myocardial Infarction (AMI) refers to myocardial necrosis caused by persistent and acute hypoxia-ischemia of the coronary artery, which is characterized by acute onset, rapid progression, diverse complications, and a high mortality rate [1]. In this article, we analysed the clinical data of 127 AMI patients who were treated in the Critical Care Unit (CCU) of our center from January $1^{\text {st }}, 2010$ to December $31^{\text {st }}, 2014$, in an attempt to identify the effective nursing strategies and provide evidence to prevent AMI deaths.

The case-fatality rate of AMI is particularly high among patients with accompanying severe arrhythmia, shock, or heart failure [2]. As AMI is highly fatal, timely and effective nursing care should be provided to manage the risk factors of AMI death, which is particularly important for improving the survival rate of AMI patients. Hence, how to give the corresponding nursing strategies for the risk factors of death is the focus of the current clinical nursing of AMI.

\section{Materials and Methods}

\section{Aim and design}

The aim of the study was to investigate the risk factors of AMI caused death and discuss the corresponding nursing strategies. We conducted a retrospective analysis.

\section{Participants and data collection}

A convenience sample of AMI patients was recruited. The inclusion criteria were newly diagnosed, hospitalized and Electrocardiogram (ECG) diagnosis AMI patients. The exclusion criteria were having on blood routine examination or detailed nursing record data. AMI patients treated from January $1^{\text {st }}, 2010$ to December $31^{\text {st }}, 2014$ in our center were enrolled and categorized into observed group and control group according to psychological counseling. Demographic and clinical data, including age, gender, education background, medical history (history of myocardial infarction, hypertension, and/or diabetes), predisposing factors (e.g., pulmonary 
infection, physical activity, unstable mood, vomiting, and urination), chief complaints were obtained and analysed.

\section{AMI diagnostic criteria}

AMI was diagnosed according to the AMI diagnostic criteria established by the American College of Cardiology in 2000, which includes the following: a) acute and severe chest pain lasting for more than $20 \mathrm{~min}$, which cannot be alleviated by nitroglycerin; b) abnormal Q waves persist on ECG; or, QS wave occurs in two or more leads for more than $24 \mathrm{~h}$; and c) serum troponin, myoglobin and creatine kinase isoenzyme levels are more than twice the normal values.

\section{Statistical analysis}

All data were analysed using the SPSS software package (SPSS version 19.0, Chicago, IL, USA). The measurement data are presented as means or medians, and the count data as frequency or percentage. The multivariate logistic regression model analysis was used to identify the association of the proportional hazards and the risk factors of AMI deaths. $p$ value $<0.05$ was considered statistically significant.

\section{Results}

\section{General data}

Of the 127 patients recruited in this study, 74 were male and 53 were female, with an average age of $71 \pm 7.87$ y. 68 patients were enrolled into observed group and 59 in control group. The clinical features of patients were summarized in Table 1. Total of $48(70.6 \%)$ of observed group had complicated infection and $43(72.9 \%)$ of control group, respectively. The mortality of observed group was $17.65 \%$, significantly lower than $33.90 \%$ of control group $(\mathrm{p}=0.035)$.

\section{Variable assignment for risk factors of $\mathrm{AMI}$ deaths}

The general data and clinical data of the 127 patients were summarized in Table 2. Several risk factors were assigned in this study, including gender, age, education background, awareness, incentive, hypertension history, diabetes history, coronary heart disease history, renal failure history, accompanying infection, infracted area, arrhythmias, cardiogenic shock, prognosis, psychological counseling, etc. All of the above risk factors would be used for the logistic regression analysis for investigating the independent predictors for death of AMI patients.

\section{A binary logistic regression model analysis of independent predictors of death among AMI patients}

A binary logistic-regression model was used to determine independent predictors of good outcome and death. In binary logistic-regression analysis, independent predictors of AMI death were age $\geq 70 \mathrm{y}$, concurrent infection, infarct size, subsequent cardiogenic shock, as is shown in Table3.

Table 1. The clinical features of 127 AMI patients.

\begin{tabular}{lll}
\hline Characteristic & NO. $(\%)$ of patients & $p$ \\
& value
\end{tabular}

\begin{tabular}{|c|c|c|c|c|}
\hline & $\begin{array}{l}\text { All } \\
(n=127)\end{array}$ & $\begin{array}{l}\text { Observation } \\
\text { group }(n=68)\end{array}$ & $\begin{array}{l}\text { Control group } \\
(n=59)\end{array}$ & \\
\hline Age, y & $\begin{array}{l}71.23 \pm \\
7.87\end{array}$ & $72.63 \pm 10.32$ & $67.76 \pm 12.11$ & \\
\hline \multicolumn{5}{|l|}{ Sex } \\
\hline Male & 74 & 38 & 36 & 0.558 \\
\hline Female & 53 & 30 & 23 & \\
\hline \multicolumn{5}{|l|}{ Education } \\
\hline Illiteracy & 38 & 21 & 17 & - \\
\hline Grade/Junior high & 67 & 38 & 29 & \\
\hline $\begin{array}{l}\text { High school or } \\
\text { above }\end{array}$ & 22 & 9 & 13 & \\
\hline
\end{tabular}

Awareness

\begin{tabular}{lllll}
\hline Yes & 54 & 22 & 32 & $0.013^{*}$ \\
\hline No & 73 & 46 & 27 & \\
\hline
\end{tabular}

Hypertension

\begin{tabular}{|c|c|c|c|c|}
\hline Yes & 98 & 50 & 48 & 0.295 \\
\hline No & 29 & 18 & 11 & \\
\hline $\begin{array}{l}\text { Coronary } \\
\text { disease }\end{array}$ & heart & & & \\
\hline Yes & 76 & 38 & 38 & 0.328 \\
\hline No & 51 & 30 & 21 & \\
\hline
\end{tabular}

Diabetes mellitus

\begin{tabular}{lllll}
\hline Yes & 48 & 28 & 20 & 0.399 \\
\hline No & 79 & 40 & 39 &
\end{tabular}

Renal dysfunction

\begin{tabular}{lllll}
\hline Yes & 27 & 12 & 15 & 0.285 \\
\hline No & 100 & 56 & 44 &
\end{tabular}

\begin{tabular}{|c|c|c|c|c|}
\hline \multicolumn{5}{|l|}{ Infection } \\
\hline Yes & 91 & 43 & 48 & 0.024 \\
\hline No & 36 & 25 & 11 & \\
\hline \multicolumn{5}{|l|}{ Infarct localization } \\
\hline Single site & 89 & 52 & 38 & 0.05 \\
\hline Wide site & 38 & 16 & 21 & \\
\hline \multicolumn{5}{|l|}{ Incentive } \\
\hline Infection & 49 & 22 & 27 & - \\
\hline Physical activity & 20 & 11 & 9 & \\
\hline Emotional stress & 21 & 12 & 9 & \\
\hline Satiation & 7 & 5 & 2 & \\
\hline Micturition & 5 & 2 & 3 & \\
\hline
\end{tabular}




\begin{tabular}{lcccc}
\hline Unknown & 25 & 16 & 9 & \\
\hline Arrhythmia & & & & 0.056 \\
\hline Yes & 49 & 21 & 28 & \\
\hline No & 78 & 47 & 31 & \\
\hline \multicolumn{2}{l}{ Cardiogenic shock } & & & \\
\hline
\end{tabular}

\begin{tabular}{lllll}
\hline Yes & 28 & 10 & 18 & $0.032^{*}$ \\
\hline No & 99 & 58 & 41 & \\
\hline Prognosis & & & & $0.035^{*}$ \\
\hline Death & 32 & 12 & 20 & \\
\hline Improvement & 95 & 56 & 39 &
\end{tabular}

Table 2. Variable assignment for risk factors of AMI deaths.

\begin{tabular}{|c|c|c|c|c|c|}
\hline Independent variable & \multicolumn{5}{|l|}{ Assignment } \\
\hline Gender & \multicolumn{5}{|l|}{ 1=Male; $2=$ Female } \\
\hline Age & \multicolumn{5}{|l|}{$1<70$ y; $2 \geq 70 y$} \\
\hline Education background & \multicolumn{5}{|c|}{$1=$ =Illiterate; $2=$ =elementary or junior high school; 3=high school or above } \\
\hline Awareness & \multicolumn{5}{|l|}{$1=$ No; 2 = Yes or somehow } \\
\hline Incentive & \multicolumn{5}{|l|}{$0=\mathrm{No} ; 1=\mathrm{Yes}$} \\
\hline History of hypertension & \multicolumn{5}{|l|}{$0=\mathrm{No} ; 1=\mathrm{Yes}$} \\
\hline History of diabetes & \multicolumn{5}{|l|}{$0=\mathrm{No} ; 1=$ Yes } \\
\hline History of coronary heart disease & \multicolumn{5}{|l|}{$0=\mathrm{No} ; 1=$ Yes } \\
\hline History of renal failure & \multicolumn{5}{|l|}{$0=\mathrm{No} ; 1=$ Yes } \\
\hline Accompanying infection & \multicolumn{5}{|l|}{$0=$ No; $1=$ Yes } \\
\hline Infarcted area & \multicolumn{5}{|c|}{$1=$ Single site; $2=$ Multiple site, diffuse } \\
\hline Arrhythmias & \multicolumn{5}{|l|}{$0=\mathrm{No} ; 1=$ Yes } \\
\hline Cardiogenic shock & \multicolumn{5}{|l|}{$0=$ No; $1=$ Yes } \\
\hline Prognosis & \multicolumn{5}{|l|}{$0=$ Alive $; 1=$ Dead } \\
\hline Psychological counseling & \multicolumn{5}{|l|}{$0=$ No; $1=$ Yes } \\
\hline \multirow{2}{*}{\multicolumn{2}{|c|}{$\begin{array}{l}\text { Table 3. Multivariate Cox proportional hazards regression analysis of } \\
\text { risk factors of AMI deaths. }\end{array}$}} & Cardiogenic shock ${ }^{*}$ & $0.014^{*}$ & 0.277 & $0.053-1.436$ \\
\hline & & ${ }^{*} p<0.05,{ }^{* * *} p<0.001$ & & & \\
\hline
\end{tabular}

\begin{tabular}{|c|c|c|c|}
\hline Impact factors & $p$ value & OR & $95 \% \mathrm{Cl}$ \\
\hline Sex & 0.478 & 1.468 & $0.498-4.433$ \\
\hline Age $^{*}$ & $0.002^{* * *}$ & 0.178 & $0.061-0.518$ \\
\hline \multirow[t]{2}{*}{ Education } & 0.258 & 0.377 & $0.070-2.044$ \\
\hline & 0.602 & 0.672 & $0.150-3.002$ \\
\hline Awareness $^{*}$ & $0.016^{*}$ & 5.946 & $1.401-25.229$ \\
\hline Incentive & 0.384 & 0.529 & $0.126-2.218$ \\
\hline Hypertension & 0.802 & 0.85 & $0.239-3.028$ \\
\hline Coronary heart disease & 0.674 & 1.319 & $0.363-4.791$ \\
\hline Diabetes mellitus & 0.898 & 0.917 & $0.244-3.444$ \\
\hline Renal dysfunction & 0.414 & 0.466 & $0.075-2.906$ \\
\hline Infarct localization ${ }^{*}$ & $0.035^{*}$ & 0.96 & $0.144-6.415$ \\
\hline Infection* & $0.026^{*}$ & 0.193 & $0.045-0.824$ \\
\hline Arrhythmia & 0.661 & 0.724 & $0.171-3.063$ \\
\hline
\end{tabular}

\section{Discussion}

Our study indicated that age $\geq 70 \mathrm{y}$, awareness, concurrent infection, infarct size, subsequent cardiogenic shock were independent predictors of AMI death. The correlations between patient factors (e.g. gender (male), age and education background) and AMI death were consistent with other national and international research [3-5]. Elderly patients typically have poor physical status, underlying chronic diseases, poor treatment response and poor tolerance to treatment. Once AMI occurs, the poor compensation, regeneration, and repair capabilities of myocardial cells in these patients prevent a reduction in infarct size, thus deteriorating the condition $[3,6,7]$. Moreover, elderly patients usually have lower immune system defense function and are easy to merge infection, especially pulmonary infection, which may affect the respiratory function and increase the burden of heart. Those patients often have poor prognosis [8]. Patients with a low education background tend to have poor knowledge and awareness of health and medicine, since they are mainly 
from rural areas with poor socioeconomic conditions and lack sufficient knowledge of the disease and its early identification and self-management. Thus, AMI in these patients is often not timely and effectively treated [9]. Cardiac output may decrease sharply following AMI. The accompanying arrhythmia, heart failure, cardiogenic shock, and hypotension are the most common and most severe clinical symptoms and are also the main causes of death, especially when there is severe ventricular arrhythmia [10]. Hypokalemia, hypotension, myocardial ischemia, congestive heart failure, and atrioventricular block can trigger ventricular arrhythmias. When the arrhythmia or hypotension is difficult to improve, myocardial ischemia/hypoxia can be aggravated, along with further expanded infarct size and worsening of disease.

As AMI is characterized by acute onset, rapid progression and a high mortality rate, effective treatment and nursing is the key to reduce the motility and improve prognosis. We analyse the corresponding nursing strategies associated with above risk factors, so as to provide measures timely and effectively, and clinical thought to advance the treatment success rate.

Firstly, maintaining patients on strict bed rest with stable mood. As we seen in this study, exercise, tiredness, recurring pre-cordial pain, vomiting, and poor rest are common predisposing factors for AMI. The most common symptom of AMI is chest pain [11]. In the present study, all 32 patients were admitted due to persistent precordial pain, and presented with acute painful face, anxiety and fear. Vomiting, tiredness, and poor rest could increase cardiac load and myocardial oxygen consumption, thus inducing AMI. As emergency care was immediately administered by nurses to patients on admission, psychological nursing may be neglected. In addition, the frequently visit by their family members and friends may lead to insufficient rest and sleep of patients. Thus, careful psychological counselling and adequate and uninterrupted sleep are essential in reducing myocardial oxygen consumption and may play a therapeutic role in lowering the mortality rate. Specific measures include: 1. Efforts should be made to create a good environment for rest. Ideally, patients should be provided with a single room in a quiet ward with fresh air and soft light; daily care should be provided by a specially-assigned staff, and the number of visiting guests should be limited. Psychological nursing is of particular importance. A relatively unfamiliar environment and emergency rescue measures such as oxygen inhalation, ECG monitoring, and infusion may induce fear in patients, who assume that they are critically ill. Focusing on their mental status, nurses should educate the patients regarding the purpose and significance of nursing care so as to eliminate their worries, and family members can be instructed to encourage patients to restore their confidence. For restless and anxious patients, appropriate sedation therapy may be provided as well. Multiple nursing procedures should be carried out jointly to ensure the adequate rest of the patients. 2. Nursing measures for preventing pain are passive exercise, oxygen inhalation during the acute phase (3-4 L/min), the administration of lactulose ( 1 bag per night) and food choices with most fiber. The bowels should be kept open. In case of any symptom (e.g. chest tightness and palpitations) mimicking heart attack before defecation, nitroglycerin should be administered sublingually first. Patients with frequent pain attacks should be managed with a nitroglycerin intravenous drip as nitrates can dilate veins; cardiac preload, left ventricular end-diastolic pressure and myocardial oxygen consumption should be reduced, and left ventricular function improved locally and globally [12]. 3. Nausea and vomiting in AMI patients are associated with stimulation of the vagus nerve by the necrotic myocardium and with inadequate tissue perfusion due to decreased cardiac output [13]. Nurses should ensure the frequent small meals and snacks of patients and keep the stomach warm. If necessary, metoclopramide tablets may be taken to reduce vomiting.

Secondly, continuous ECG monitoring is also one of the important nursing intervention. Typically, nurses should report any arrhythmias found on ECG to the physician and then perform symptomatic management according to the physician's orders. In patients with ventricular extra-systole, drugs may be administered orally to slow ventricular rhythm; in patients with ventricular tachycardia, an immediate intravenous injection of lidocaine $(50 \mathrm{mg})$ is required, and in patients with ventricular fibrillation, unsynchronized DC cardio-version at an energy level of 200-300 W-s should be performed. Third-degree atrioventricular block is often treated with drugs that can increase the ventricular rate [14]. Early use of anti-arrhythmic drugs or the implantation of a temporary pace-maker following AMI are essential for the prevention and treatment of arrhythmia.

Close observation of disease changes should be administered. The potential occurrence of acute heart failure and cardiogenic shock should be monitored. In our series, 14 patients developed heart failure and 15 had cardio-genic shock, in whom 2-3 venous channels were established according to the physician's orders to control the dripping speed, to avoid aggravating or inducing heart failure. For patients with cardiogenic shock, vasodilator drugs and presser drugs should be used simultaneously. The dripping speed of vasodilator drugs and presser drugs should be adjusted from time to time based on the dynamic change in blood pressure. A micro-injection pump is preferred as it can control both the dripping speed and the total volume of rehydration. The total volume of liquid should be approximately $1500 \mathrm{ml} / \mathrm{d}$, with a dripping speed of $\leq$ $30 \mathrm{drops} / \mathrm{min}$, and salt intake should be limited. In our series, AMI deaths mainly occurred in four time periods: morning, noon, evening, and night, probably related to the fact that physical activities increase during eating. Moreover, the blood participates in digestion after meals, resulting in decreased effective circulating volume, which leads to increased cardiac load and decreased blood supply to the myocardium. AMI occurring in the morning and at night may be due to an imbalance between sympathetic nerves and parasympathetic nerves, which increases catecholamine content and thus affects the electrical activity of cardiac muscle cells. A slow and bland diet and frequent small meals are expected for patients. Sufficient human resources should be available for a double shift and night shift. When patients are at meals or at bedtime, nurses should assist the patients to care themselves and closely monitor any changes in disease condition. Besides, most 
patients in our series were the elderly with more common complications. Elderly AMI patients are at higher risk for complications including coronary perforation, bundle branch block, congestive heart failure, stroke, kidney dysfunction, and bleeding $[15,16]$. For patients with persistent and recurring severe clinical pain, changes in heart rate, cardiac rhythm, ECG findings, and myocardial enzymes should also be closely monitored. Any progression in MI should be timely reported to the physicians. Eleven of our patients suffered from unanticipated sudden respiratory and cardiac arrest. Therefore, for patients with large infarct size, hypotension, and unfavorable ECG findings (e.g., ventricular tachycardia, ventricular fibrillation, or third-degree atrio-ventricular block), nurses should intensify the ward round and observe the condition change, and make bedside first-aid medicine and appliance available for patients.

Finally, enhancing health education should be taken specifically. Patients have low awareness of emergency management. In our series, 8 patients were hospitalized due to multiple sites of large MI; 16 patients were admitted one day after the occurrence of pre-cordial pain; and 14 patients from other cities were sent to our hospital directly without receiving any first-aid procedures in local facilities; and 9 patients were transferred from local hospitals during the acute phase, where the disease was not timely treated or controlled, and excessive tiredness during the long trip worsened the condition. These patients were critically ill at admission, threatening an extremely high rate of case-fatality. Thus, nurses are supposed to recognize that the transfer process is a major contributing factor in nearly $70 \%$ of adverse medical events [16]. During health education, patients and their families should be informed that AMI must be treated immediately at onset or during the acute phase. Health education should also be tailored. For patients with a low education background, the dangers of AMI and the importance of timely medical treatment should be repeatedly emphasized [17,18]. Selfmanagement after disease onset may also be taught. For instance, once the disease occurs, patients should sit down immediately and take vasodilators such as nitroglycerin and compound salvia droplet pill orally. They should stay calm; if the condition permitting, oxygen inhalation may be carried out at home, and emergency call of 120 should be made immediately for ambulance care. Besides, underlying chronic medical diseases require regular medical treatment. In our series, 21 patients had coronary heart disease, 16 had hypertension, 4 had diabetes, and 3 suffered from chronic renal failure. In most cases, the disease awareness rate, treatment rate, and/or medication adherence were low. Therefore, for elderly patients at high risk of cardiovascular diseases, special attention should be paid to the risk of AMI $[3,15,16]$. The discharge instructions for the patients should cover attending regular outpatient follow-up visit, taking medicine according to the doctor's orders, changing unhealthy lifestyles, and seeking medical treatment if the disease recurs. As we know, in winter when it is colder and drier, with sharp temperature differences, vasoconstriction may occur, leading to slow blood flow, hemoconcentration, platelet aggregation, and thrombus formation
$[19,20]$. In addition, upper respiratory tract infection is a predisposing factor for AMI. In our series, AMI was induced by upper respiratory/lung infection in 10 patients. Therefore, AMI patients should keep warm during winter and spring to avoid upper respiratory/lung infection. Finally, patients should be assisted to urinate or defecate in bed. Also, they should be reminded not to retain urine, and the volume of urine passed each time should be $\leq 1000 \mathrm{ml}$. In our series, AMI suddenly worsened following urination in 3 cases.

\section{Conclusion}

In summary, we analysed the clinical data of 127 AMI patients and proposed that nurses should pay special attention to first aid, disease monitoring, and nursing of AMI patients. In addition, three-tier prevention of underlying chronic conditions such as coronary heart disease, hypertension, diabetes, and chronic renal failure is important to control the risk factors of AMI. During their daily activities, patients should keep optimistic and cheerful, take sufficient rest and keep warm to avoid predisposing factors. Also, tailored health education should be provided to patients and their families, in particular, awareness and knowledge of disease identification and selfmanagement, in order to avoid delayed diagnosis and shorten hospital stay. What's more, concurrent infection of AMI patients may indicate a poor prognosis. These comprehensive nursing strategies, such as psychological counseling may help to decrease AMI deaths and improve patient prognosis.

\section{Conflict of Interests}

None

\section{Acknowledgement}

None

\section{References}

1. Otsuki Y, Nakamura Y, Harada S, Yamamoto Y, Ogino K, Orikawa K, Ninomiya H, Miyagawa S, Sawa Y, Hisatome I, Nishimura M. Adipose stem cells sheets improved cardiac function in the rat myocardial infarction, but did not alter cardiac contractile response to beta-adrenergic stimulation. Biomed Res 2015; 36: 11-19.

2. Cui H, Hu YX, Fan L, Ye P, Yang TS, Zhao YS, Li XY. Influence of in-hospital occurrence of organ failure on the prognosis of acute myocardial infarction in the elderly patients: an analysis of 2,535 cases. Zhongguo Wei Zhong Bing Ji Jiu Yi Xue 2010; 22: 295-298.

3. Gharacholou SM, Lopes RD, Alexander KP, Mehta RH, Stebbins AL, Pieper KS, James SK, Armstrong PW, Granger CB. Age and outcomes in ST-segment elevation myocardial infarction treated with primary percutaneous coronary intervention: findings from the APEX-AMI trial. Arch Intern Med 2011; 171: 559-567.

4. Miura T, Miyashita Y, Motoki H, Shimada K, Kobayashi M, Nakajima H, Kimura H, Akanuma H, Mawatari E, 
Sato T, Hotta S, Kamiyoshi Y, Maruyama T, Watanabe N, Eisawa T, Aso S, Uchikawa S, Hashizume N, Sekimura N, Morita T, Ebisawa S, Izawa A, Tomita T, Koyama J, Ikeda U. In-hospital clinical outcomes of elderly patients $(\geq 80$ years) undergoing percutaneous coronary intervention. Circ J 2014; 78: 1097-1103.

5. Tehrani DM, Darki L, Erande A, Malik S. In-hospital mortality and coronary procedure use for individuals with dementia with acute myocardial infarction in the United States. J Am Geriatr Soc 2013; 61: 1932-1936.

6. Kukreja N, Onuma Y, Garcia-Garcia H, van Nierop J, Daemen J, van Domburg R, Serruys PW. Three-year clinical event rates in different age groups after contemporary percutaneous coronary intervention. Euro Interv 2011; 7: 969-976.

7. Bogomolov AN, Kozlov KL, Kurochkina ON, Olesiuk IB. Coronary stenting in elderly patients with acute myocardial infarction (review). Adv Gerontol 2013; 26: 151-160.

8. Kalousova M, Zima T, Krane V, Marz W, Wanner C, Tesar V, Drechsler C. Pregnancy-associated plasma protein A associates with cardiovascular events in diabetic hemodialysis patients. Atherosclerosis 2014; 236: 263-269.

9. Kirchberger I, Heier M, Wende R, von Scheidt W, Meisinger $\mathrm{C}$. The patients interpretation of myocardial infarction symptoms and its role in the decision process to seek treatment: the MONICA/KORA Myocardial Infarction Registry. Clin Res Cardiol 2012; 101: 909-916.

10. Gooden JY, Scantlebury D, Asirvatham S. An unrecognized, preventable cause of syncope, malignant arrhythmia, and cardiac death. JAMA Intern Med 2013; 173: 1915-1917.

11. Parodi G. Editors choice-chest pain relief in patients with acute myocardial infarction. Eur Heart J Acute Cardiovasc Care 2016; 5: 277-281.

12. Strandmark R, Herlitz J, Axelsson C, Claesson A, Bremer A, Karlsson T, Jimenez-Herrera M, Ravn-Fischer A. Determinants of pre-hospital pharmacological intervention and its association with outcome in acute myocardial infarction. Scand J Trauma Resusc Emerg Med 2015; 23: 105.

13. Kirchberger I, Heier M, Goluke H, Kuch B, von Scheidt W, Peters A, Meisinger C. Mismatch of presenting symptoms at first and recurrent acute myocardial infarction. From the MONICA/KORA Myocardial Infarction Registry. Eur J Prev Cardiol 2016; 23: 377-384.
14. Gang UJ, Jons C, Jorgensen RM, Abildstrom SZ, Messier MD, Haarbo J, Huikuri HV, Thomsen PE. Risk markers of late high-degree atrioventricular block in patients with left ventricular dysfunction after an acute myocardial infarction: a CARISMA substudy. Europace 2011; 13: 1471-1477.

15. Lichtman JH, Wang Y, Jones SB, Leifheit-Limson EC, Shaw LJ, Vaccarino V, Rumsfeld JS, Krumholz HM, Curtis JP. Age and sex differences in inhospital complication rates and mortality after percutaneous coronary intervention procedures: evidence from the NCDR((R)). Am Heart J 2014; 167: 376-383.

16. Dziewierz A, Siudak Z, Rakowski T, Dubiel JS, Dudek D. Age-related differences in treatment strategies and clinical outcomes in unselected cohort of patients with STsegment elevation myocardial infarction transferred for primary angioplasty. J Thromb Thrombolysis 2012; 34: 214-221.

17. Abed MA, Ali RM, Abu Ras MM, Hamdallah FO, Khalil AA, Moser DK. Symptoms of acute myocardial infarction: a correlational study of the discrepancy between patients expectations and experiences. Int J Nurs Stud 2015; 52: 1591-1599.

18. Brokalaki H, Giakoumidakis K, Fotos NV, Galanis P, Patelarou E, Siamaga E, Elefsiniotis IS. Factors associated with delayed hospital arrival among patients with acute myocardial infarction: a cross-sectional study in Greece. Int Nurs Rev 2011; 58: 470-476.

19. Rivero A, Bolufe J, Ortiz PL, Rodriguez Y, Reyes MC. Influence of climate variability on acute myocardial infarction mortality in Havana, 2001-2012. MEDICC Rev 2015; 17: 14-19.

20. Aytekin M, Aulak KS, Haserodt S, Chakravarti R, Cody J, Minai OA, Dweik RA. Abnormal platelet aggregation in idiopathic pulmonary arterial hypertension: role of nitric oxide. Am J Physiol Lung Cell Mol Physiol 2012; 302: 512-520.

\section{*Correspondence to}

Li-Ping Cui

Department of Cardiovascularology

The First Affiliated Hospital of Medical University of Anhui

PR China 